\title{
The effects of instrument-assisted soft tissue mobilization rehabilitation exercise on range of motion, isokinetic strength, and balance in chronic ankle instability taekwondo players
}

\author{
Jong-Hoon Park', Hyun-Seung Rhyu'², Soung-Yob Rhi',* \\ 'Departments of Sports \& Health Management, Catholic Kwandong University, Gangnung, Korea \\ ${ }^{2}$ Department of Physical Education, Jungwon University, Goesan, Korea
}

We aimed to investigate change the instrument-assisted soft tissue mobilization (IASTM) rehabilitation exercise on range of motion (ROM), isokinetic ankle strength, and balance. We included 20 elite taekwondo players (chronic ankle instability) in Korea. They were divided into the IASTM group $(n=10)$, control group $(n=10)$. IASTM group were exercised with IASTM rehabilitation exercise four times per week for 8 weeks. The remaining control group did not receive exercise intervention between tests and served as the control. A goniometer was used to measure dorsi-flexion (D/F), plantar-flexion (P/F), a dynamometer was used to measure ankle isokinetic strength, and plantar foot pressure was used to measure static balance. The data were analyzed using repeated-measures analysis of variance. Significant differences were observed between the two groups in IASTM group and control group: ROM (right $P / F, P<0.001$; right $D / F, P<0.01$; left $P / F, P<0.000$; left $\mathrm{D} / \mathrm{F}, P<0.000$ ), isokinetic strength (right $\mathrm{P} / \mathrm{F} 60^{\circ}, P<0.000$; right $\mathrm{D} / \mathrm{F} 60^{\circ}$, $P<0.000$; left $\mathrm{P} / \mathrm{F} 60^{\circ}, P<0.000$; left $\mathrm{D} / \mathrm{F} 60^{\circ}, P<0.000$; right $\mathrm{P} / \mathrm{F} 180^{\circ}$, $P<0.000$; right $\mathrm{D} / \mathrm{F} 180^{\circ}, P<0.000$; left: $P / F 180^{\circ}, P<0.000$, left $\mathrm{D} / \mathrm{F} 180^{\circ}$, $P<0.000$ ), and balance test (static eye open, $P<0.000$; static eye close, $P<0.000$; postural stability, $P<0.041)$. These results suggest that IASTM rehabilitation exercise improves ankle stability, muscle power, and body balance in chronic ankle instability taekwondo players.

Keywords: Instrument-assisted soft mobilization, Range of motion, Static balance, Isokinetic strength

\section{INTRODUCTION}

Taekwondo is a sport where the outcome of the match is determined by using the limbs of the body to strike the opposing player and earn points (Jeong et al., 2019). The attacking techniques of taekwondo are categorized into those either using the hands or feet. In particular, the movements of the lower limbs during competitive matches are repetitive and complex in a short span of time (Slimani et al., 2007). The complex movements in taekwondo consist of many functional forms such as the double kick, directionchange, footwork, and roundhouse kick, and these movements are mostly adjusted and controlled by the feet. As a result, there are several cases of injuries in the lower limbs of the athletes. Repeti- tive injuries can lead to chronic ankle instability, causing a decrease in flexibility, strength, balance, and proprioceptive sensibility.

The foot movement from the taekwondo athletes requires support from the standing foot, footwork-skill from the kicking foot, and stability and balance to maintain posture (Son et al., 2018). These movements are centered around the ankle and as a result, they can lead to restrictions in the joint's range of motion (ROM), muscle weakness, and decrease in proprioception sensibility, eventually leading to ankle instability (Sekir et al., 2007). Additionally, the unique footwork, jumps, and landing in taekwondo cause repetitive supination and pronation, leading to shortening of the Achilles heel and weakness in the tibialis anterior and peroneus muscles, thus hindering the balance of the feet. The chronic ankle
${ }^{*}$ Corresponding author: Soung-Yob Rhi (iD https://orcid.org/0000-0002-0278-9442 Departments of Sports \& Health Management, Catholic Kwandong University,

24 Beomil-ro 579beon-gil, Gangnung 25601, Korea

E-mail: fltmdduq@cku.ac.kr

Received: October 16, 2020 / Accepted: November 24, 2020
This is an Open Access article distributed under the terms of the Creative Commons Attribution Non-Commercial License (https://creativecommons.org/licenses/by-nc/4.0/) which permits unrestricted non-commercial use, distribution, and reproduction in any medium, provided the original work is properly cited. 
instability comprises $40 \%-50 \%$ of the lower limb injuries (Bridge et al., 2014; Fong and Ng, 2011).

Chronic ankle instability has a clear impact on the muscular strength of the ankle, therefore, training regimes focus on the strengthening of these muscles around the ankle. However, recent research has shown that if the ROM and flexibility in the ankle are not recovered first, then it is difficult to strengthen the muscles around the ankle and the reoccurrence rate of the same injury also increases (Flores et al., 2011). Additionally, the recovery of the ankle's ROM helps to stimulate the proprioception and muscle contraction of the ankle, accelerates the rotational speed, and increases the muscular strength of the ankle (Schwesig et al., 2016). As a result, the recovery of a healthy ankle ROM has a correlative relationship with the muscular strength of the ankle (McKean and Burkett, 2009).

The application of instrument-assisted soft tissue mobilization (IASTM) on an ankle affected by the chronic ankle instability, stimulates cellular reconstruction of the infection, tendon, muscles, and other tissue structures in the area (Ikeda et al., 2019). Additionally, IASTM can alleviate pain associated with the muscle and ligament, promote regular ROM, and structurally and functionally treat the damaged area (Cheatham et al., 2016). Overall, IASTM has a positive effect on the nervous system and body function of the specific area (Seffrin et al., 2019). However, in the current state of scientific research, inadequate research has been done on the use of IASTM.

Thus, we investigated the effects in ROM, isokinetic strength, balance by applying IASTM rehabilitation exercise. We providing data for precise and appropriate chronic ankle instability rehabilitation exercise.

\section{MATERIALS AND METHODS}

\section{Subjects}

The subjects were 20 male chronic ankle instability taekwondo plyers from Bucheon city. This study was approved by the Institu-

Table 1. Subject characteristics (male, $\mathrm{N}=20$ )

\begin{tabular}{lrr}
\hline Characteristic & IASTME $(\mathrm{n}=10)$ & \multicolumn{1}{c}{ CON $(\mathrm{n}=10)$} \\
\hline Age $(\mathrm{yr})$ & $17.80 \pm 0.78$ & $17.80 \pm 0.63$ \\
Weight $(\mathrm{kg})$ & $69.34 \pm 5.73$ & $70.18 \pm 3.99$ \\
Height $(\mathrm{cm})$ & $174.12 \pm 4.11$ & $168.68 \pm 6.07$ \\
Body fat $(\%)$ & $13.03 \pm 8.04$ & $12.22 \pm 6.68$ \\
Body mass & $20.99 \pm 1.81$ & $22.09 \pm 2.57$ \\
\hline
\end{tabular}

Values are presented as mean \pm standard deviation.

IASTM, instrument-assisted soft tissue mobilization group; CON, control group. tional Review Board of Catholic Kwandong University (approval number: CKU-20-02-0210). They were classified into the IASTM rehabilitation exercise group (IASTM, $\mathrm{n}=10$ ), and the control group (CON, $n=10)$. All subjects were informed of the experimental purpose and procedures and signed a consent form. The physical characteristics of the subjects are shown in Table 1.

\section{IASTM rehabilitation exercise protocol}

IASTM rehabilitation exercise protocol in this study is shown in Table 2. The IASTM rehabilitation program (used Graston Technique: Strum, Brush, Fan, Sweep) was adjusted and based on the precedent study done by Stanek et al. (2018) and Ikeda et al. (2019). In the protocol, between each workout, there was a 1-min rest period with a total of $70 \mathrm{~min}$ of exercise done daily, thrice a week for a span of 8 weeks.

\section{Measurement of ankle joint ROM}

This study used the goniometer (Sammons Preston, Bolingbrook, IL, USA) to measure the overall ROM of the ankle by measuring the dorsi-flexion $(\mathrm{D} / \mathrm{F})$ and plantar-flexion $(\mathrm{P} / \mathrm{F})$ of the ankle. The $\mathrm{D} / \mathrm{F}$ was measured by placing the axis of the goniometer at the lateral malleus bone while the stationary arm was placed parallel at the outer line of the fibula and movement arm parallel at the outer side of the 5 th metatarsal. Then, the dorsum of the foot was pulled towards the fibula to measure the degree of $\mathrm{D} / \mathrm{F}$. The $\mathrm{P} / \mathrm{F}$ was measured by placing the axis of the goniometer at the lateral malleus bone while the stationary arm was placed parallel at the outer line of the fibula and movement arm parallel to the outer side of the 5 th metatarsal. Then, the sole of the foot was pushed away from the fibula to measure the degree of $\mathrm{P} / \mathrm{F}$.

\section{Measurement of isokinetic strength}

This study used an isokinetic equipment to measure the $\mathrm{D} / \mathrm{F}$ and P/F of the ankle (Isoforce, SungDo MC Co., Seoul, Korea). The participants were placed in a supine position on the isokinetic

Table 2. IASTM rehabilitation exercise protocol

\begin{tabular}{|c|c|c|c|}
\hline Position & Type & Technique & Time (min) \\
\hline Warm-up (IASTM) & $\begin{array}{l}\text { Gastrocnemius, Soleus, Achilles } \\
\text { tendon }\end{array}$ & Strum/Brush & 10 \\
\hline $\begin{array}{l}\text { Ankle exercise } \\
\text { (IASTM) }\end{array}$ & $\begin{array}{l}\text { Ankle (D/F, P/F, IV, EV) } \\
\text { Ankle circles }\end{array}$ & $\begin{array}{l}\text { Strum/Fan } \\
\text { Strum/Sweep }\end{array}$ & 40 \\
\hline Cool-down (walking) & Back walking & Treadmill & 20 \\
\hline
\end{tabular}

IASTM, instrument-assisted soft tissue mobilization; D/F, dorsi-flexion; P/F, plantar-flexion; IV, inversion; EV, eversion. 
measuring chair. Following this, the lateral malleus bone was placed at the rotation of the measuring device by adjusting the slope and height of the chair. When the flexion was being measured, the femoral and precordial regions were fixed to prevent any additional effort being exerted through these areas. To prevent any adverse reaction to the isokinetic device, the participants were informed and trained for the specific motion. The applied protocol in the examination was eight repetitions at the angular speed of $60^{\circ} / \mathrm{sec}$ and 20 repetitions at $180^{\circ} / \mathrm{sec}$.

\section{Measurement of balance}

This study measured static balance using a plantar foot pressure measuring device. The static balance was measured in a static state with the eyes opened (static eye open, SEO), the eyes closed (static eye close, SEC) and with the postural stability (PS). The SEO and SEC were measured with the participants having their feet at shoulder width, in a standing position with both arms placed on the side of the thighs and facing forward. The PS was calculated using the measured values of the SEO and SEC.

\section{Statistical analyses}

All data are expressed as mean and standard deviation using IBM SPSS Statistics ver. 22.0 (IBM Co., Armonk, NY, USA). The one sample Kolmogorov-Smirnov test was conducted to examine normality. The equal variance test was conducted using Levene's equal variance F-test. ROM, isokinetic ankle strength, and balance were measured in the 20 subjects, and repeated-measures analysis of variance was to examine the relationships between the groups and the measured variables. Statistical significance was accepted for $P$-values $<0.05$.

Table 3. Results of the range of motion analysis (unit: ${ }^{\circ}$ )

\begin{tabular}{lcccccc}
\hline \multirow{2}{*}{ Trial } & & Group & Pretest & Posttest & \multicolumn{2}{c}{ Interaction (group × time) } \\
\cline { 6 - 7 } & & & & & $F$ & $P$-value \\
\hline Right & P/F & IASTM & $45.10 \pm 1.37$ & $41.70 \pm 2.31$ & 16.200 & $0.001^{* * *}$ \\
& & CON & $42.60 \pm 4.64$ & $41.90 \pm 4.30$ & & \\
& D/F & IASTM & $15.30 \pm 3.19$ & $23.00 \pm 2.35$ & 6.974 & $0.01^{*}$ \\
& & CON & $16.20 \pm 2.85$ & $18.60 \pm 2.45$ & & \\
Left & P/F & IASTM & $44.90 \pm 2.46$ & $41.80 \pm 1.68$ & 36.922 & $0.000^{* * *}$ \\
& & CON & $41.70 \pm 3.46$ & $41.50 \pm 3.50$ & & \\
& D/F & IASTM & $17.20 \pm 2.48$ & $22.60 \pm 1.89$ & 36.481 & $0.000^{* * *}$ \\
& & CON & $15.90 \pm 2.64$ & $16.00 \pm 2.40$ & & \\
\hline
\end{tabular}

Values are presented as mean \pm standard deviation.

$\mathrm{P} / \mathrm{F}$, plantar-flexion; D/F, dorsi-flexion; IASTM, instrument-assisted soft tissue mobilization group; $\mathrm{CON}$, control group.

${ }^{*} P<0.05$. ${ }^{* *} P<0.001$.

\section{RESULTS}

\section{Measurement of ankle joint ROM}

Table 3 shows the changes in ankle ROM. The ROM at ankle joint $\mathrm{D} / \mathrm{F}$ and $\mathrm{P} / \mathrm{F}$ in the two groups. Significant differences were observed between the IASTM and CON groups during $\mathrm{D} / \mathrm{F}$ of right and left feet $(F=6.974, P<0.01 ; F=36.481, P<0.000$, respectively) before and after the experiment. Significant differences were observed between the IASTM and CON groups during P/F of right and left feet $(F=16.200, P<0.001 ; F=36.922, P<0.000$, respectively) before and after the experiment.

\section{Measurement of isokinetic strength}

Tables 4 and 5 show the result of isokinetic ankle strength mea-

Table 4. Results of the isokinetic strength $\left(60^{\circ} / \mathrm{sec}\right)$

\begin{tabular}{|c|c|c|c|c|c|c|}
\hline \multirow[t]{2}{*}{ Trial } & & \multirow[t]{2}{*}{ Group } & \multirow[t]{2}{*}{ Pretest } & \multirow[t]{2}{*}{ Posttest } & \multicolumn{2}{|c|}{$\begin{array}{l}\text { Interaction } \\
\text { (group } \times \text { time) }\end{array}$} \\
\hline & & & & & $F$ & $P$-value \\
\hline \multirow[t]{4}{*}{ Right } & $\mathrm{P} / \mathrm{F} 60^{\circ} / \mathrm{sec}$ & IASTM & $33.81 \pm 12.74$ & $90.31 \pm 15.85$ & 28.479 & $0.000^{* * *}$ \\
\hline & & CON & $30.91 \pm 11.12$ & $53.60 \pm 10.16$ & & \\
\hline & $\mathrm{D} / \mathrm{F} 60^{\circ} / \mathrm{sec}$ & IASTM & $32.33 \pm 6.47$ & $73.57 \pm 6.74$ & 38.800 & $0.000^{* * *}$ \\
\hline & & CON & $31.86 \pm 8.59$ & $51.52 \pm 10.05$ & & \\
\hline \multirow[t]{4}{*}{ Left } & $\mathrm{P} / \mathrm{F} 60^{\circ} / \mathrm{sec}$ & IASTM & $26.29 \pm 7.44$ & $115.09 \pm 31.00$ & 66.568 & $0.000^{* * *}$ \\
\hline & & CON & $36.92 \pm 11.47$ & $58.84 \pm 12.30$ & & \\
\hline & $\mathrm{D} / \mathrm{F} 60^{\circ} / \mathrm{sec}$ & IASTM & $28.37 \pm 5.54$ & $92.46 \pm 14.21$ & 39.533 & $0.000^{* * *}$ \\
\hline & & CON & $25.58 \pm 7.17$ & $54.01 \pm 9.62$ & & \\
\hline
\end{tabular}

Values are presented as mean \pm standard deviation.

$\mathrm{P} / \mathrm{F}$, plantar-flexion; D/F, dorsi-flexion; IASTM, instrument-assisted soft tissue mobilization group; $\mathrm{CON}$, control group.

${ }^{* * *} P<0.001$

Table 5. Results of the isokinetic strength $\left(180^{\circ} / \mathrm{sec}\right)$

\begin{tabular}{|c|c|c|c|c|c|c|}
\hline \multirow[t]{2}{*}{ Trial } & & \multirow[t]{2}{*}{ Group } & \multirow[t]{2}{*}{ Pretest } & \multirow[t]{2}{*}{ Posttest } & \multicolumn{2}{|c|}{$\begin{array}{l}\text { Interaction } \\
\text { (group ×time) }\end{array}$} \\
\hline & & & & & $F$ & $P$-value \\
\hline \multirow[t]{4}{*}{ Right } & $\mathrm{P} / \mathrm{F} 180^{\circ} / \mathrm{sec}$ & IASTM & $23.04 \pm 6.18$ & $90.59 \pm 8.85$ & 42.635 & $0.000^{* * *}$ \\
\hline & & CON & $29.02 \pm 11.47$ & $61.76 \pm 8.05$ & & \\
\hline & $\mathrm{D} / \mathrm{F} 180^{\circ} / \mathrm{sec}$ & IASTM & $27.13 \pm 4.88$ & $87.66 \pm 12.56$ & 55.462 & $0.000^{* * *}$ \\
\hline & & $\mathrm{CON}$ & $26.31 \pm 6.72$ & $46.66 \pm 13.24$ & & \\
\hline \multirow[t]{4}{*}{ Left } & $\mathrm{P} / \mathrm{F} 180^{\circ} / \mathrm{sec}$ & IASTM & $34.79 \pm 18.08$ & $101.01 \pm 16.78$ & 58.744 & $0.000^{* * *}$ \\
\hline & & CON & $34.03 \pm 14.65$ & $50.08 \pm 5.66$ & & \\
\hline & $\mathrm{D} / \mathrm{F} 180^{\circ} / \mathrm{sec}$ & IASTM & $26.38 \pm 8.19$ & $84.31 \pm 8.14$ & 27.927 & $0.000^{* * *}$ \\
\hline & & CON & $26.06 \pm 6.32$ & $54.32 \pm 9.39$ & & \\
\hline
\end{tabular}

Values are presented as mean \pm standard deviation.

$\mathrm{P} / \mathrm{F}$, plantar-flexion; D/F, dorsi-flexion; IASTM, instrument-assisted soft tissue mobilization group; $\mathrm{CON}$, control group.

${ }^{* * *} P<0.001$. 
Table 6. Results of the static balance analysis

\begin{tabular}{llcccc}
\hline \multirow{2}{*}{ Trial } & Group & Pretest & Posttest & \multicolumn{2}{c}{ Interaction (group ×time) } \\
\cline { 6 - 6 } & & & & $F$ & $P$-value \\
\hline SEO $(\mathrm{mm})$ & IASTM & $80.80 \pm 8.62$ & $53.10 \pm 5.72$ & 22.983 & $0.000^{* * *}$ \\
& CON & $81.40 \pm 7.87$ & $75.30 \pm 8.19$ & & \\
SEC (mm) & IASTM & $91.30 \pm 3.71$ & $59.00 \pm 12.90$ & 39.663 & $0.000^{* * *}$ \\
& CON & $90.60 \pm 4.03$ & $89.10 \pm 3.81$ & & \\
PS (sec) & IASTM & $6.18 \pm 1.59$ & $2.79 \pm 0.65$ & 4.847 & $0.041^{*}$ \\
& CON & $5.02 \pm 2.58$ & $4.38 \pm 2.06$ & & \\
\hline
\end{tabular}

Values are presented as mean \pm standard deviation.

SEO, static eye open; SEC, static eye close, PS: posture stability; IASTM, instrument-assisted soft tissue mobilization group; $\mathrm{CON}$, control group.

${ }^{*} P<0.05 .{ }^{* *} P<0.001$.

surement. Significant differences were showed in peak torque $\%$ body before and after the experiment at $60 \%$ sec of right angular speed in $\mathrm{D} / \mathrm{F}(F=38.800, P<0.000)$ and $\mathrm{P} / \mathrm{F}(F=28.479, P<0.000)$ and at $180^{\circ} / \mathrm{sec}$ of right angular speed in $\mathrm{D} / \mathrm{F}(F=39.533, P<$ $0.000)$ and $\mathrm{P} / \mathrm{F}(F=55.462, P<0.000)$. Significant differences were showed in peak torque $\%$ body before and after the experiment at $60 \%$ sec of left angular speed in $\mathrm{D} / \mathrm{F}(F=39.533, P<0.000)$ and $\mathrm{P} / \mathrm{F}(F=66.568, P<0.000)$ and at $180^{\circ} / \mathrm{sec}$ of left angular speed in $\mathrm{D} / \mathrm{F}(F=27.927, P<0.000)$ and $\mathrm{P} / \mathrm{F}(F=58.744, P<0.000)$.

\section{Measurement of balance}

Table 6 shows the changes in static balance ability. Significant differences were observed in the SEO $(F=22.983, P<0.000)$, SEC $(F=39.663, P<0.000)$, and PS $(F=4.847, P<0.041)$ test between the IASTM and CON groups before and after the experiment.

\section{DISCUSSION}

Excellent performance of taekwondo requires balance, flexibility, and muscle power of the body. Flexibility among those factors has a lot of connections to performance (Dupont et al., 2004). However, excessive flexibility of the ankle increases the injury of the ankle (Jovanovic et al., 2011). In particular, chronic instability of ankles showed D/F reduction and P/F increase (Simone et al., 2019). There was a significant difference in the dorsal and plantar-flexion of the taekwondo athletes between the control and rehabilitation groups after the IASTM rehabilitation (right $\mathrm{P} / \mathrm{F}, F=16.200, P<$ 0.001 ; right $\mathrm{DF}, F=6.974, P<0.01$; left $\mathrm{P} / \mathrm{F}, F=36.922, P<0.000$; left $\mathrm{D} / \mathrm{F}, F=36.481, P<0.000)$. Similar results have also been reported by Terada et al. (2013), who reported that the use of the muscle relaxation technique helped stimulate the conglutinated area of the ankle, improve the ROM, and alleviate pain by releas- ing the structural pressure of the affected area in individuals with feet pain and a restricted ROM in the ankles (Imai et al., 2015). Additionally, this technique created microinjuries in the conglutinated area to stimulate the recovery of the area and positively affected the ROM in the ankles. Another study conducted by Schaefer and Sandrey (2012) distributed chronic ankle instability participants into three groups (Graston Tech. group, dynamic stretching group, and control group) for a total of 3 weeks. In this regard, results of this study reported that compared to the dynamic stretching group, the Graston group and dynamic stretching group had improvements in balance and ankle function through the restimulation of the ligament where the fibroblast recovery phase was halted. In addition, these improvements of ankle function provide ankle stability for chronic ankle instability players (Simone et al., 2019). As a result, the precedent studies corroborate the findings in this study and the following results show that IASTM can be effectively used to improve the ROM of the ankles through the stimulative recovery of injured ligaments and muscles causing chronic ankle instability in taekwondo players.

Isokinetic muscular strength is generated from a constant speed and specific motion and is a fundamental muscular strength required by every athlete (Dauty et al., 2016). It also interacts through movement to represent stability. In taekwondo athletes, the center of gravity is placed in the forefoot of both feet and the excessive use and exhaustion of the soleus, gastrocnemius, tibialis anterior, and long peroneal muscles can cause muscle tension and an impairment in the ROM, thereby leading to a decrease in muscular strength (Giulio et al., 2009). Hertel (2002) showed that the severity of chronic instability can increase due to repetitive injury; however, constant stimulation of ankle joint muscles can lead to an increase in muscular strength and improvement in mobility. Thereby, increasing the stability of the ankle. In this study showed that there is a significant difference in the isokinetic ankle joint muscular strength between the IASTM rehabilitation and control groups (in plantar-flexion, at the right and left-foot angular velocities of $60 \%$ sec, $F=28.479, P<0.0001, F=66.568, P<0.0001$; $180^{\circ} / \mathrm{sec}, F=42.635, P<0.0001, F=58.744, P<0.0001$; in dorsiflexion, $60^{\circ} / \mathrm{sec}, F=38.800, P<0.0001, F=39.533, P<0.0001$; $\left.180^{\circ} / \mathrm{sec}, F=55.462, P<0.0001, F=27.927, P<0.0001\right)$. A precedent study conducted by Van den Tillaar and Ettema (2009) reported that there is a correlative relationship between the angular speed of rotation, muscular strength, and ROM in the ankle. These results are consistent with those of the present study, and as a result, a muscle relaxation technique can improve the ROM and muscular strength of the ankle, and stimulate the movement in 
the ankle to improve muscular mobilization. Thus, it was assumed in this study that the constant stimulation and improvement in the ROM played a role in the improvement of the isokinetic muscular strength in the ankle.

For taekwondo athletes, balance is established through minimizing the standing posture and base surface and maintaining a high center of gravity (Brachman et al., 2017). When a kick is performed, the proprioceptive senses are required to control the movement of the body (Fong and Ng, 2011; Han et al., 2015). This study showed that there was a statistically significant difference in the ability to balance between the rehabilitation and control groups. According to precedent studies, an impairment in the sensory capability can also impair balance (Pasma et al., 2015). A study by Mecagni et al. (2000) investigated the relationship between the ROM in the ankles and ability to balance and showed that ankle exercises improving its ROM also influenced the ability to balance and prevent further injuries. Additionally, a study investigated the relationship between the ROM in the ankles and lower muscular strength with static eye open balance and found that static balance is determined by stability of the ankles, which is affected by the muscular strength and ROM of the ankles (Kim and Kim, 2018). These results correspond to those of a previous study that reported that the balance of SEO and SEC has higher and PS increase, which improves body balance. Balance ability in the body of the IASTM group participants significantly improved as follow: in $\operatorname{SEO}(F=22.983, P<0.0001), \operatorname{SEC}(F=39.663, P<$ $0.0001)$, and PS $(F=4.847, P<0.05)$. It is believed that the significant difference found in the rehabilitation group in this study can be explained by the indirect improvement of balance through the improvement in the ROM and proprioceptive senses of the ankles. Based on these results, an IASTM rehabilitation exercise program can improve ankle balance, and to maintain this improve, it would be necessary to using the IASTM exercise program continually during the training in chronic ankle instability taekwondo players.

In this study, the IASTM rehabilitation exercise improved the ROM of ankle joint, isokinetic muscle strength, and balance of the chronic ankle instability taekwondo players. Thus, sustained use of an IASTM rehabilitation exercise is determined necessary for improving ankle instability and effective athletics care in not only young taekwondo players but also other age in chronic ankle instability athletes. As with any study, there are minor two limitations in this study. First, because the subjects were recruited from one high school in South Korea, they do not represent the entire Korean taekwondo players. In addition, the subjects com- prised a limited number of high school students $(\mathrm{N}=20)$. Second, because various training methods and rehabilitation techniques are applied to each person through IASTM it is difficult to conclude that exactly the same treatment exercise has been applied to all the taekwondo players.

\section{CONFLICT OF INTEREST}

No potential conflict of interest relevant to this article was reported.

\section{REFERENCES}

Brachman A, Kamieniarz A, Michalska J, Pawłowski M, Słomka KJ, Juras G. Balance training programs in athletes - a systematic review. J Hum Kinet 2017;58:45-64.

Bridge CA, Ferreira da Silva Santos J, Chaabène H, Pieter W, Franchini E. Physical and physiological profiles of taekwondo athletes. Sports Med 2014;44:713-733.

Cheatham SW, Lee M, Cain M, Baker R. The efficacy of instrument assisted soft tissue mobilization: a systematic review. J Can Chiropr Assoc 2016;60:200-211.

Dauty M, Menu P, Fouasson-Chailloux A, Ferréol S, Dubois C. Prediction of hamstring injury in professional soccer players by isokinetic measurements. Muscles Ligaments Tendons J 2016;6:116-123.

Dupont G, Akakpo K, Berthoin S. The effect of in-season, high-intensity interval training in soccer players. J Strength Cond Res 2004;18:584589.

Flores DF, Gentil P, Brown LE, Pinto RS, Carregaro RL, Bottaro M. Dissociated time course of recovery between genders after resistance exercise. J Strength Cond Res 2011;25:3039-3044.

Fong SS, Ng GY. Does Taekwondo training improve physical fitness? Phys Ther Sport 2011;12:100-106.

Giulio ID, Maganaris CN, Baltzopoulos V, Loram ID. The proprioceptive and agonist roles of gastrocnemius, soleus and tibialis anterior muscles in maintaining human upright posture. J Physiol 2009;587(Pt 10): 2399-2416.

Han J, Anson J, Waddington G, Adams R, Liu Y. The role of ankle proprioception for balance control in relation to sports performance and injury. Biomed Res Int 2015;2015:8.

Hertel J. Functional anatomy, pathomechanics, and pathophysiology of lateral ankle instability. J Athl Train 2002;37:364-375.

Ikeda N, Otsuka S, Kawanishi Y, Kawakami Y. Effects of instrument-assisted soft tissue mobilization on musculoskeletal properties. Med Sci Sports Exerc 2019;51:2166-2172. 
Imai K, Ikoma K, Chen Q, Zhao C, An KN, Gay RE. Biomechanical and histological effects of augmented soft tissue mobilization therapy on Achilles tendinopathy in a rabbit model. J Manipulative Physiol Ther 2015;38:112-118.

Jeong HS, O'Sullivan DM, Lee SC, Lee SY. Safety evaluation of protective equipment for the forearm, shin, hand and foot in taekwondo. J Sports Sci Med 2019;18:376-383.

Jovanovic M, Sporis G, Omrcen D, Fiorentini F. Effects of speed, agility, quickness training method on power performance in elite soccer players. J Strength Cond Res 2011;25:1285-1292.

Kim SG, Kim WS. Effect of ankle range of motion (ROM) and lower-extremity muscle strength on static balance control ability in young adults: a regression analysis. Med Sci Monit 2018;24:3168-3175.

McKean M, Burkett BD. The relationship between joint range of motion, muscular strength, and race time for sub-elite flat water kayakers. J Sci Med Sport 2009;13:537-542.

Mecagni C, Smith JP, Roberts KE, O'Sullivan SB. Balance and ankle range of motion in community-dwelling women aged 64 to 87 years: a correlational study. Phys Ther 2000;80:1004-1011.

Pasma JH, Engelhart D, Maier AB, Schouten AC, van der Kooij H, Meskers CG. Changes in sensory reweighting of proprioceptive information during standing balance with age and disease. J Neurophysiol 2015; 114:3220-3233.

Schaefer JL, Sandrey MA. Effects of a 4-week dynamic-balance-training program supplemented with graston instrument-assisted soft-tissue mobilization for chronic ankle instability. J Sport Rehabil 2012;21:313326.

Schwesig R, Hermassi S, Wagner H, Fischer D, Fieseler G, Molitor T, Delank
KS. Relationship between the range of motion and isometric strength of elbow and shoulder joints and ball velocity in women team handball players. J Strength Cond Res 2016;30:3428-3435.

Seffrin CB, Cattano NM, Reed MA, Gardiner-Shires AM. Instrument-assisted soft tissue mobilization: a systematic review and effect-size analysis. J Athl Train 2019;54:808-821.

Sekir U, Yildiz Y, Hazneci B, Ors F, Aydin T. Effect of isokinetic training on strength, functionality and proprioception in athletes with functional ankle instability. Knee Surg Sports Traumatol Arthrosc 2007;15: 654-664.

Simone B, Giacomo L, Antonio S, Andrea E, Marco Z, Aurélie MM, Antonio $S$. Sport injury prevention in individuals with chronic ankle instability: Fascial Manipulation ${ }^{\circledR}$ versus control group: a randomized controlled trial. J Bodyw Mov Ther 2019;23:316-323.

Slimani M, Chaabene H, Miarka B, Chamari K. The activity profile of elite low-kick kickboxing competition. Int J Sports Physiol Perfor 2007;12: 182-189.

Son MJ, Youm CH, Woo JW, Lee MG, Kim YY, Kim JH. Postural stability for taekwondo athletes with repetitive ankle sprains during a singleleg stance. J Phys Ther Sci 2018;30:405-410.

Stanek J, Sullivan T, Davis S. Comparison of compressive myofascial release and the graston technique for improving ankle-dorsiflexion range of motion. J Athl Train 2018;53:160-167.

Terada M, Pietrosimone BG, Gribble PA. Therapeutic interventions for increasing ankle dorsiflexion after ankle sprain: a systematic review. J Athl Train 2013;48:696-709.

Van den Tillaar R, Ettema G. Is there a proximal-to-distal sequence in over arm throwing in team handball? J Sports Sci 2009;27:949-955. 